\title{
Early-age volume changes of extrudable reactive powder concrete
}

\author{
K. Cherkaoui ${ }^{1,2,3}$, M. Courtial ${ }^{2,4}$, F. Dunstetter ${ }^{2}$, A. Khelidj ${ }^{3}$, P. Mounanga, ${ }^{3, a}$, and M.-N. de \\ Noirfontaine $^{2}$ \\ ${ }^{1}$ Laboratoire de Matériaux Polymères aux Interfaces, Boulevard François Mitterand, 91025 Evry \\ Cedex \\ ${ }^{2}$ Laboratoire des Solides Irradiés, Ecole Polytechnique, 91128 Palaiseau Cedex, France \\ ${ }^{3}$ GeM, UMR CNRS 6183 - Research Institute of Civil Engineering and Mechanics, 58 rue Michel \\ Ange, B.P. 420, 44606 Saint-Nazaire Cedex, France \\ ${ }^{4}$ Laboratoire d'Artois Mécanique et Habitat, Université d'Artois, route de l'Université, 62408 \\ Béthune, France
}

\begin{abstract}
This article presents a study on the early-age autogenous deformations of Extrudable Reactive Powder Concretes (ERPCs), especially designed for the making of concrete pipes by extrusion. Different ERPC mixtures, with variable amounts of polycarboxylate superplasticizer (SP), have been investigated. Results on 28-day mechanical properties, early-age hydration rate, autogenous shrinkage and premature cracking risk are analyzed and discussed in relation with the ERPC mix parameters.
\end{abstract}

\section{Introduction}

Reactive powder concretes (RPCs) constitute a particular type of cementitious materials developed in the early 1990s [1-3] and characterized by ultra-high mechanical performances and very low permeability. After a specific heat treatment, their compressive strength lies between $200 \mathrm{MPa}$ and $800 \mathrm{MPa}$. The proportioning principles of RPCs are based on the optimization of the microstructure obtained by combining fines particles (Portland cement, crushed filler, silica fume, sand) in the range of 0.02 to 600 microns, very low water-to-cement ratio and important amount of high-range waterreducing superplasticizer [1]. RPC are mainly used in major civil engineering projects and concrete structures such as bridges or airports [3].

In this research work, we study the behaviour of Extrudable Reactive Powder Concretes (ERPCs) especially designed for the making of concrete pipes. Extrusion is a common forming process for a wide range of materials (food, polymer, clay and metal). For cement-based matrices, extrusion could be a high productivity forming process, particularly adapted in the case of firm materials $[4,5]$.

Different ERPC mixtures, with variable amounts of polycarboxylate superplasticizer (SP), silica fume and crushed quartz, have been investigated. The extrudability of the ERPCs was previously checked through extrusion tests at different compression speeds, perfomed with a $50-\mathrm{kN}$ compression testing machine, as presented in Figure 1. At the die entry of the extruder experimental

\footnotetext{
a e-mail : pierre.mounanga@univ-nantes.fr
} 
system, the material leaves in a continuous manner, proving the extrusion capacity of the RPCs investigated.

The first part of the study focuses on the early and very early age properties of ERPCs before extrusion. The effects of solid components and SP content on mechanical performances, heat flow of hydration and early-age autogenous shrinkage in free and restrained conditions were measured and analyzed in terms of premature autogenous cracking risk of the cement-based matrices.
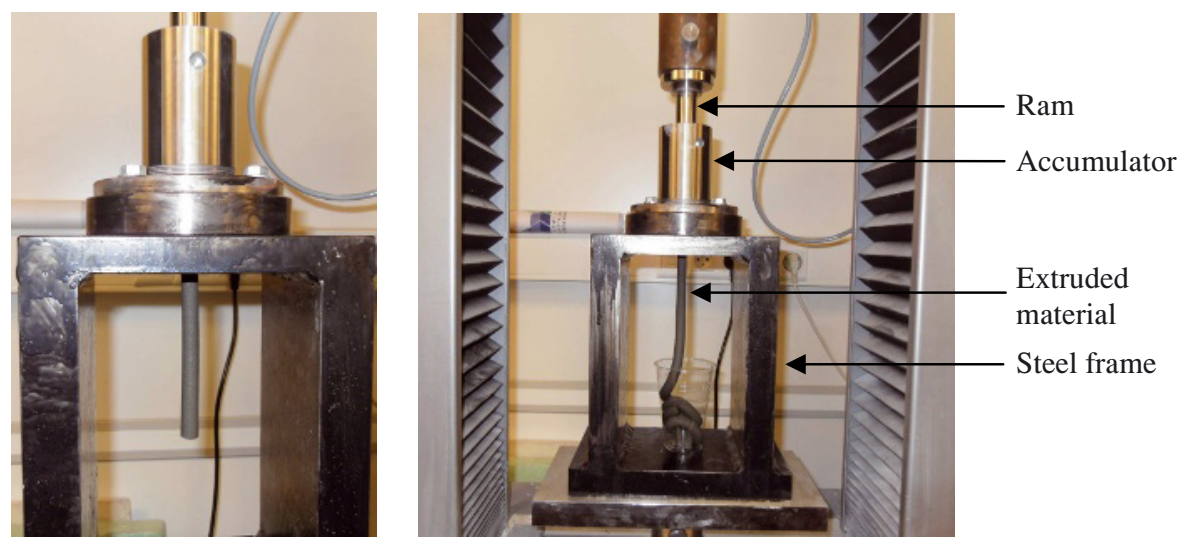

Fig. 1. Measurement of the extrudability of ERPC. Piston's diameter: $3 \mathrm{~cm}$; compression speed: $20 \mathrm{~mm} / \mathrm{min}$.

\section{Experimental program}

\subsection{Materials}

The mixtures were prepared with four solid components:

- A Portland cement of type CEM I 52,5N from Le Havre's plant (Lafarge). Its Bogue's composition is $67.5 \%$ of $\mathrm{C}_{3} \mathrm{~S}, 10.7 \%$ of $\mathrm{C}_{2} \mathrm{~S}, 2.64 \%$ of $\mathrm{C}_{3} \mathrm{~A}, 12.8 \%$ of $\mathrm{C}_{4} \mathrm{AF}$ and $3.3 \%$ of gypsum;

- Silica fume containing $93.5 \%$ of $\mathrm{SiO}_{2}$, commercialized by Condensil;

- Crushed quartz of type Millisil C400 and siliceous sand of type CV32, provided by Sibelco.

The particle size distribution of the materials, measured by laser granulometry, is plotted in Figure 2; their specific surface area and density are given in Table 1.

A modified-polycarboxylate high-range water-reducing superplasticizer was used to improve the workability of the mixtures, at constant water-to-cement (W/C) ratio. We utilized the Cimfluid 2002 (Axim) in liquid form (dry matter: $35 \%$ ).

Table 1. Fineness and density of the solid components.

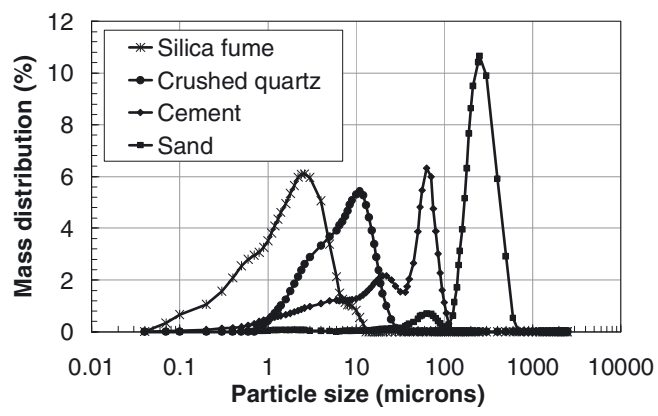

\begin{tabular}{|c|c|c|}
\hline Materials & $\begin{array}{c}\text { Specific } \\
\text { surface area } \\
\left(\mathbf{m}^{\mathbf{2}} \mathbf{/ k g}\right)\end{array}$ & $\begin{array}{c}\text { Density } \\
\left(\mathbf{g} / \mathbf{c m}^{\mathbf{3}}\right)\end{array}$ \\
\hline Silica fume & 14000 & 2.20 \\
\hline Crushed quartz & 693 & 2.65 \\
\hline Cement & 382 & 3.20 \\
\hline Sand & 12.6 & 2.65 \\
\hline
\end{tabular}

Fig. 2. Particle size distribution of the solid components of ERPCs. 


\subsection{Mixtures}

Five different ERPCs were investigated, three of them being prepared with Portland cement, silica fume, sand, superplasticizer (SP) and water, and the two other mixtures incorporating, in addition, crushed quartz. The compositions were selected in order to study the effects of SP dosage and crushed quartz, keeping a constant water-to-cement ratio. The detail of each mixture composition is provided in Table 2. The five ERPCs were manufactured by mixing the solid components with tap water in a $20-\mathrm{L}$ mixer. Concerning the introduction of the components into the mixer, mixing times and speed, the same procedure was rigorously applied for each batch. It is given in Figure 3.

Table 2. Compositions of the ERPCs, by mass.

\begin{tabular}{|c|c|c|c|c|c|c|}
\hline Mixtures & Cement & Silica fume & Crushed quartz & Sand & Superplasticizer & Water \\
\hline ERPC_1 & 1 & 0.25 & 0 & 1.1 & $0.5 \%$ & 0.16 \\
\hline ERPC_2 & 1 & 0.25 & 0 & 1.1 & $1.0 \%$ & 0.16 \\
\hline ERPC_3 & 1 & 0.25 & 0 & 1.1 & $1.8 \%$ & 0.16 \\
\hline ERPC_4 & 1 & $0.25 \quad 3 / 4$ & $0.25 \quad 1 / 4$ & 1.1 & $1.8 \%$ & 0.16 \\
\hline ERPC_5 & 1 & $0.25 \quad 3 / 4$ & $0.25 \quad 1 / 4$ & 1.1 & $2.0 \%$ & 0.16 \\
\hline
\end{tabular}

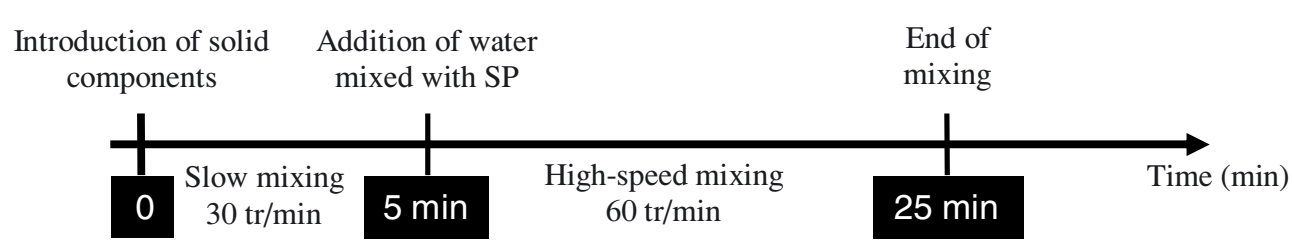

Fig. 3. Mixing procedure.

\subsection{Testing methods}

The early-age heat flow of hydration, autogenous shrinkage in free and restrained conditions, wateraccessible porosity and 28-days mechanical performances were measured. The tests were performed at $20^{\circ} \mathrm{C}$.

The early-age reaction rate of the ERPCs was quantified by isothermal microcalorimetry, with a TAM Air device. For each mixture, two 4-g specimens are taken at the end of mixing, accurately weighed and placed into ampoules. The ampoules are then sealed and placed in the apparatus. The first experimental point is acquired about ten minutes after the end of mixing.

Free autogenous shrinkage was measured with a horizontal linear experimental system (Figure 4) developed by Bouasker et al. [6]. The fresh material is cast in a moulded, tight and very flexible PVC membrane and immersed in a thermostated water bath. Waterproof contactless sensors were used to measure the specimen displacements. This method makes it possible to follow the deformations of the sample from its very early age.

Ring tests were achieved to measure the autogenous shrinkage of ERPCs in restrained conditions. The experimental device is composed of two rings - a PVC ring for the external form and a central metal ring (Young's modulus $=100 \mathrm{GPa}$ ), which acts as the internal form and restraint (Figure 4). Two aluminium plates constitute the base and the cover of the assembly, and keep the specimen in autogenous conditions. The annular specimen has a cross section of $40 \times 40 \mathrm{~mm}^{2}$ and an inner diameter of $210 \mathrm{~mm}$. The internal ring strain induced by the shrinkage of ERPCs is measured by four strain gauges, axi-symmetrically fixed at the mid-height of the inner surface of the metal rings. Four supplementary strain gauges are placed on a metal plate inside the central space for the thermal compensation. The strain gauges are connected to a data logging system in a half-bridge configuration for automatic and continuous monitoring. The ring devices are thermally regulated by 
a water circulation system connected to a thermostated water bath. Supplementary details about the experimental system can be found in [7].

The 28-day mechanical properties of ERPCs were determined on $4 \times 4 \times 16-\mathrm{cm}^{3}$ prismatic specimens kept in autogenous conditions at $20^{\circ} \mathrm{C}$ until testing. The dynamic Young's modulus was measured via impulse excitation tests with a Grindosonic ${ }^{\circledR}$ device (non-destructive method). The flexural strength was obtained from results of three-point flexural tests and the compressive strength was determined on both parts of each specimen used for flexural tests. Each test was repeated at least three times and the results obtained were used to calculate an average value of the mechanical performances.

The volume percentage of water-accessible porosity in ERPC specimens was estimated by successively measuring the mass of sample in dry state, in saturated state and in hydrostatic conditions (saturated and submerged in water) [8]. The measurements were carried out on ERPC discs (diameter: $11 \mathrm{~cm}$; thickness: $5 \mathrm{~cm}$ ).

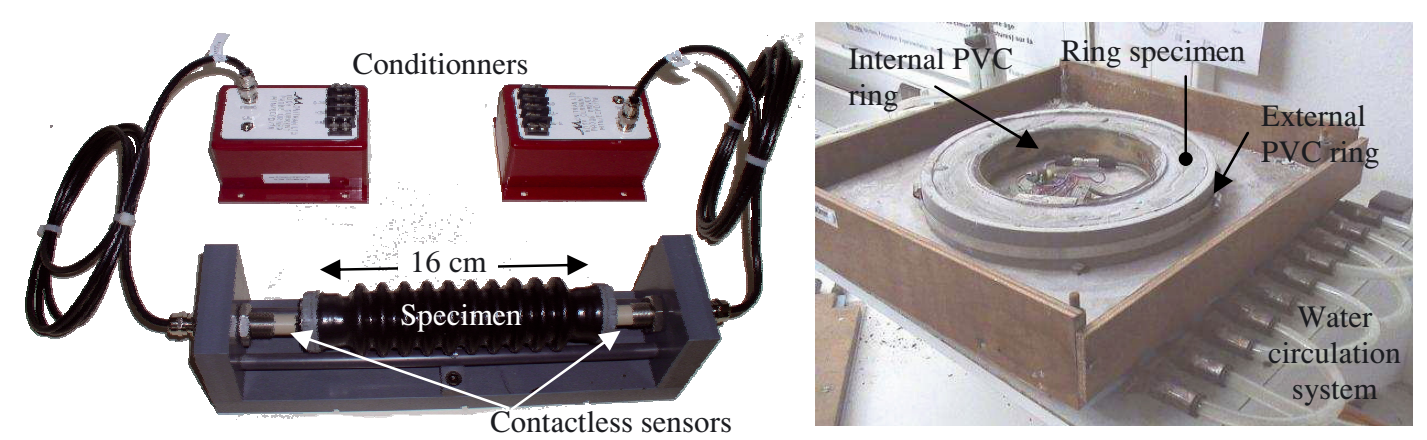

Fig. 4. Measurement devices for early-age autogenous deformations of ERPCs. Left: free linear autogenous shrinkage; right: ring test device for restrained autogenous shrinkage and evaluation of premature cracking risk.

\section{Results}

\subsection{8-day properties}

The water-accessible porosity and the mechanical performances measured at 28 days are provided in Table 3. As expected, the porosity is very low. The values obtained are close to those presented in previous studies: for example, Resplendino and Petitjean indicate water-porosity values of RPC between 1.5 and 5\% [9]. However, the absolute differences recorded between the porosity of the five ERPCs are not high enough to conclude on a particular effect of SP or crushed quartz contents.

The influence of ERPC compositions is more visible on mechanical properties. The results obtained on compressive strength are in the same range than the values given by Richard and Cheyrezy [1], for a RPC200 without fibers, cured at $20^{\circ} \mathrm{C}$, and more recently by Yazici [10]. The increase of SP content results in a significant decrease of compressive strength and a simultaneous augmentation of Young's modulus. The effect of SP content is less sensible on flexural strength.

The partial substitution of silica fume by crushed quartz leads to an increase of $25 \%$ of the compressive strength, $20 \%$ of the flexural strength and $16 \%$ of the dynamic Young's modulus, for a constant SP content. This improvement is probably due to a better granular packing of the ERPCs in presence of crushed quartz, which presents a particle size distribution intermediate between the cement and silica fume used (Figure 2). Indeed, the optimization of particle packing is the main way to obtain more homogeneous and denser cement-based matrices and greater mechanical performances $[1,11]$. 
Table 3. 28-day properties of ERPCs.

\begin{tabular}{|c|c|c|c|c|}
\hline Mixtures & $\begin{array}{c}\text { Water-accessible } \\
\text { porosity (\%) }\end{array}$ & $\begin{array}{c}\text { Dynamic Young's } \\
\text { modulus (GPa) }\end{array}$ & $\begin{array}{c}\text { Compressive strength } \\
\text { (MPa) }\end{array}$ & $\begin{array}{c}\text { Flexural strength } \\
\text { (MPa) }\end{array}$ \\
\hline ERPC_1 & 0.82 & 54.0 & 155 & 16.0 \\
\hline ERPC_2 & 0.94 & 59.1 & 150 & 15.5 \\
\hline ERPC_3 & 1.03 & 60.0 & 140 & 15.5 \\
\hline ERPC_4 & 1.61 & 69.4 & 175 & 18.6 \\
\hline ERPC_5 & 1.20 & 65.3 & 170 & 17.2 \\
\hline
\end{tabular}

\subsection{Early-age hydration rate}

Figure 5 presents the evolution of the heat flow of hydration monitored by isothermal microcalorimetry. Each curve is characterized by a dormant period with a very low evolution of the heat flow of hydration, followed by a peak marking a period of intense chemical activity: this peak generally appears during the setting of the material. The early-age chemical activity of ERPCs may be mainly attributed to Portland cement hydration, since it was shown that, at $20^{\circ} \mathrm{C}$, pozzolanic reactions of silica fume remains weak and slow during several weeks [12-14], and even nil for crushed quartz [12].

The increase of SP dosage induces an extension of the dormant period of ERPC hydration reactions. This slowing down is particularly high for ERPC_3 and also results in a significant decrease of the peak intensity of heat flow of hydration, as shown in Table 4. This secondary effect of SP on cement hydration is well-known and explained by the adsorption of the polymers on cement grains, and also by possible reactions of the $\mathrm{Ca}^{2+}$ ions with polymer anions [15], which generate a global retardation of hydration.

The presence of crushed quartz enables to partially limit the effect of SP on hydration rate: indeed, the peak of ERPC_4-curve develops about $4 \mathrm{~h}$ before that of ERPC_3 curve. This positive influence of crushed quartz on the advancement of reactions may be caused by an effect of nucleation site: Cyr et al. [16] highlighted that the presence of very fine particles (with specific surface area higher than $100 \mathrm{~m}^{2} / \mathrm{kg}$ ) could activate the cement hydration by heterogeneous nucleation. This physical process is related to the nucleation of hydrates on foreign mineral particles and causes an acceleration of early-age cement hydration and setting. Many studies have shown that silica fume also has the ability to accelerate early-age cement reactions, but Kadri et al. [17] recently shown that this accelerating effect depended on the initial water content and the substitution rate of cement with silica fume. It seems that, for the ERPCs investigated and the powder dosage considered here, crushed quartz is more efficient than silica fume in increasing early-age cement hydration.

Table 4. Characteristic values of the peak of heat flow curves.

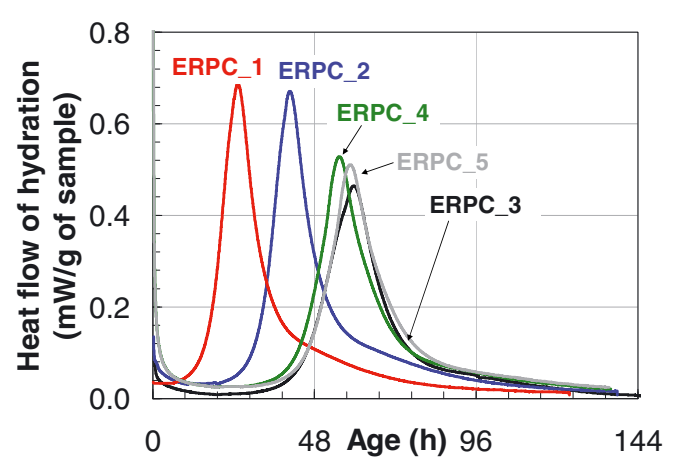

\begin{tabular}{|c|c|c|}
\cline { 2 - 3 } \multicolumn{1}{c|}{} & \multicolumn{2}{c|}{ Peak of heat flow } \\
\hline Mixtures & $\begin{array}{c}\text { Age } \\
\text { (h) }\end{array}$ & $\begin{array}{c}\text { Intensity } \\
\text { (mW/g of sample) }\end{array}$ \\
\hline ERPC_1 & 25.2 & 0.69 \\
\hline ERPC_2 & 40.7 & 0.67 \\
\hline ERPC_3 & 59.7 & 0.46 \\
\hline ERPC_4 & 55.38 & 0.53 \\
\hline ERPC_5 & 58.60 & 0.51 \\
\hline
\end{tabular}

Fig.5. Isothermal calorimetry curves of the ERPCs. 


\subsection{Free autogenous shrinkage}

Figure 6 shows the results of free autogenous shrinkage of ERPCs, at $20^{\circ} \mathrm{C}$. As the deformations are monitored from the very early-age of the materials, the autogenous shrinkage measured is a combination of chemical shrinkage and self-desiccation shrinkage [18].

Chemical shrinkage develops before the setting of the matrix: also called Le Chatelier's contraction, it mainly corresponds to the negative balance between the absolute density of hydrates and those of binder and water. The setting and the progressive water desaturation of the porous network of the material leads to a second type of deformation, called self-desiccation shrinkage. Self-desiccation is directly linked to the initial water content of the cement-based material, a lower water-to-binder ratio giving higher self-desiccation shrinkage [19]. The transition between chemical shrinkage and self-desiccation shrinkage is generally marked by a flattening of the autogenous shrinkage curve [20].

In our case, considering identical dosages of cement and water for the ERPCs studied and low reactivity of supplementary cementing materials at early-age (silica fume and crushed quartz), we can reasonably suppose that the difference of autogenous shrinkage between the ERPCs is due to the varying SP content and the partial substitution of silica fume with crushed quartz.

The setting retardation induced by the SP leads to an extension of the deformation phase dominated by chemical shrinkage. As chemical shrinkage of Portland cement is much higher than self-desiccation shrinkage, setting retardation results in a global increase of autogenous shrinkage, as shown in Figure 6: the flattening of the curves, indicating the transition from chemical to selfdesiccation shrinkage, appears later when SP content increases.

The presence of crushed quartz accelerates the hydration process and attenuates the SP retardation effect on setting. This powder probably also leads to a better particle packing and, consequently, to a re-organization of the porous network of the cementitious matrix : as the pore distribution is one of the major parameters controlling the evolution of internal relative humidity [21], the addition of crushed quartz as a way to mitigate early-age autogenous shrinkage in ERPCs, should be investigated. A third complementary explanation to lower autogenous strain of ERPC_4 is the higher Young's modulus of this mixture (Table 3): submitted to an identical internal capillary tension, it will shrink less than the other ERPCs.

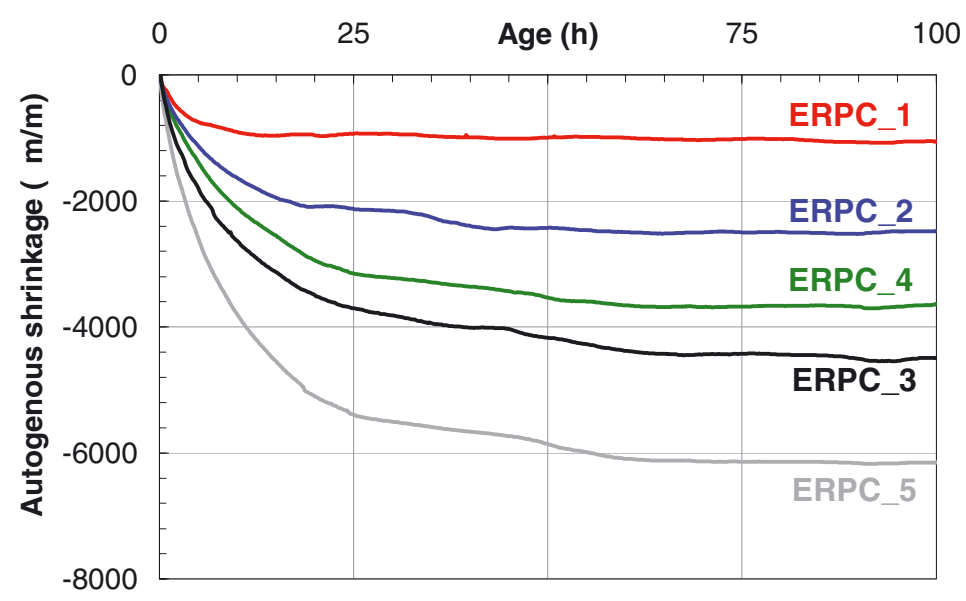

Fig.6. Free autogenous shrinkage of the ERPCs at early-age. 


\subsection{Ring test results}

The previous section focuses on free autogenous deformations of ERPCs. This type of shrinkage is particularly problematic for low water-to-cement ratio systems, since in restrained conditions, the self-induced stresses are likely to involve a premature cracking of the matrix [11]. This cracking risk should then be estimated on ERPCs, considering their very low W/C ratio.

Typical curves of restrained autogenous deformations obtained with the ring test method are shown in Figure 7.a. The tests were performed during 5 days. From these curves, it is possible to estimate the evolution of the maximal stress developing in the various ERPCs knowing the stiffness of both the cementitious matrix and the metal ring and the geometry of the experimental system [22, 23]. The maximal stress curves are given in Figure 7.b.

Each curve is characterized by a first phase of very small deformations, a second phase of accelerated strain, followed by a knee-point and a period of slower deformations. The duration of each phase depends on the composition of the ERPCs. Except for ERPC_5, the increase of SP dosage systematically causes an extension of the "mechanical" dormant period. This result is in agreement with isothermal calorimetry curves: the restrained deformations start to develop at about $26 \mathrm{~h}, 37 \mathrm{~h}, 54 \mathrm{~h}$ and $52 \mathrm{~h}$ for ERPC_1, ERPC_2, ERPC_3 and ERPC_4, respectively. These values correspond well with the time of apperance of the hydration heat flow peak (Table 4). The ERPC_5 curve does not follow the same trend, since the "mechanical" dormant period is much shorter than the dormant period observed on microcalorimetry curve: this result, probably related to the high autogenous shrinkage and Young's modulus of this mixture, will need further investigations.

It is important to note that both SP dosage and presence of crushed quartz do not significantly modify the "final" restrained deformations of the five ERPCs investigated. It should also be noticed that we did not observe through cracks at the end of the period of investigation. In fact, the maximal stresses in the different ERPCs never exceed 2.5 MPa and the early-age mechanical properties of ERPCs are high enough to resist this level of tensile stress. It should therefore be interesting to study the behaviour of these ERPCs submitted to greater tensile stress since their very early age.

a)
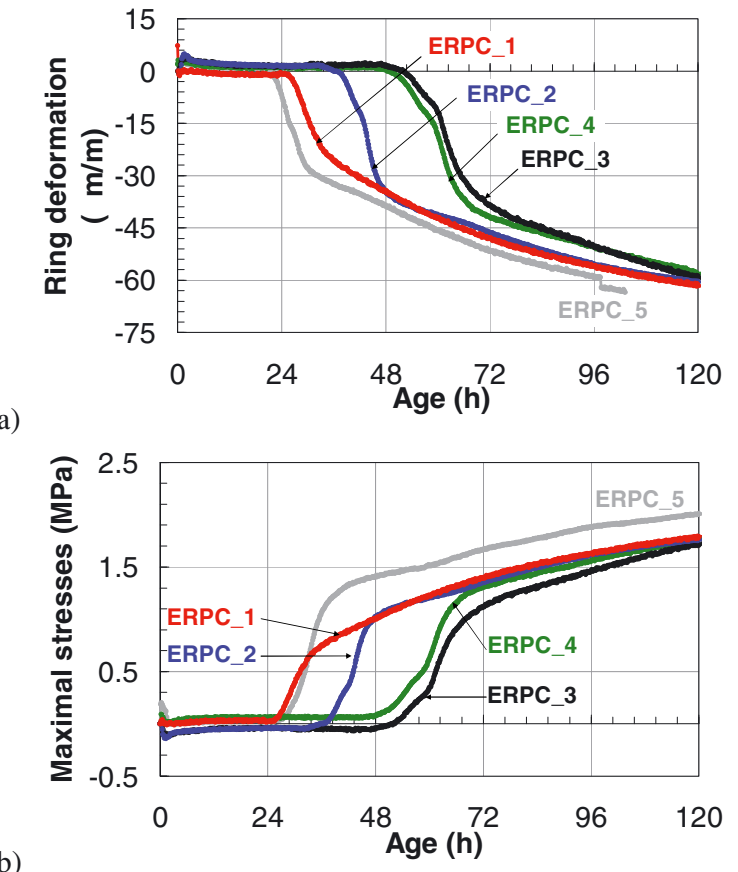

Fig. 7. Ring test curves of the ERPCs; a) Deformations of the internal metal ring, b) Maximal stresses in the ring specimens. 


\section{Conclusions and further work}

In this study, the early-age autogenous deformations and the 28-day mechanical performances of five extrudable reactive powder concretes (ERPCs) were investigated. The analysis of the results obtained leads to the following conclusions:

- The partial substitution of silica fume by crushed quartz leads to an increase of $25 \%$ of the compressive strength, $20 \%$ of the flexural strength and $16 \%$ of the dynamic Young's modulus, for a constant superplasticizer (SP) content. This improvement is probably due to a better granular packing of the ERPC matrix in presence of crushed quartz;

- The increase of SP dosage induces an extension of the dormant period of ERPC hydration reactions. The presence of crushed quartz enables to partially limit the effect of SP on hydration rate. This positive influence of crushed quartz on the advancement of reactions may be probably caused by a nucleation site effect;

- The setting retardation induced by the SP leads to an extension of the deformation phase dominated by chemical shrinkage. As chemical shrinkage of Portland cement is much higher than self-desiccation shrinkage, setting retardation results in a global increase of autogenous shrinkage. For a constant SP dosage, the partial replacement of silica fume with crushed quartz results in a diminution of autogenous shrinkage;

- $\quad$ Ring tests performed on ERPCs did not hightlight a potential premature cracking risk of these cementitious matrices.

Further tests will focus on both studying the behaviour of these ERPCs submitted to greater tensile stress since their very early age, and determining their mechanical properties after extrusion.

\section{References}

1. P. Richard, M. Cheyrezy, Cem. Concr. Res. 25, 1501 (1995)

2. P. Richard, M. Cheyrezy, ACI Special Publication 144, 507 (1994)

3. P.-C. Aïtcin, Cem. Concr. Res. 30, 1349 (2000)

4. A. Perrot, C. Lanos, Y. Melinge, P. Estellé, Rheol. Acta 46, 1065 (2007)

5. X. Qian, X. Zhou, B. Mu, Z. Li, Cem. Concr. Res. 33, 1575, (2003)

6. M. Bouasker, P. Mounanga, A. Khelidj, R. Coué, Adv. Cem. Res. 20, 75 (2008)

7. A. Pertué, P. Mounanga, A. Khelidj, D. Fournol, ICEM 13 (Alexandroupolis, 2007)

8. A. Ben Fraj, M. Kismi, P. Mounanga, Constr. Build. Mater. 24, 1069 (2010)

9. J. Resplendino, J. Petitjean, Test and design methods for steel fibre reinforced concrete: background and experiences, (RILEM Publications, Bagneux, 2003)

10. H. Yazici, Build. Env. 42, 2083 (2007)

11. K.L. Scrivener, R.J. Kirkpatrick, Cem. Concr. Res. 38, 128 (2008)

12. H. Zanni, M. Cheyrezy, V. Maret, S. Philippot, P. Nieto, Cem. Concr. Res. 26, 93 (1996)

13. S. Mansoutre, N. Lequeux, Adv. Cem. Res. 8, 175 (1996)

14. A. Loukili, A. Khelidj, P. Richard, Cem. Concr. Res. 29, 577 (1999)

15. M.Y.A. Mollah, W.J. Adams, R. Schennach, D.L. Cocke, Adv. Cem. Res. 12, 153 (2000)

16. M. Cyr, P. Lawrence, E. Ringot, Cem. Concr. Res. 36, 264 (2006)

17. E.H. Kadri, R. Duval, S. Aggoun, S. Kenai, ACI Mater. J. 106, 107 (2009)

18. A. Feylessoufi, F. Cohen Tenoudji, V. Morin, P. Richard, Cem. Concr. Res. 31, 1573 (2001)

19. V. Baroghel-Bouny, P. Mounanga, A. Khelidj, A. Loukili, N. Rafaï, Cem. Concr. Res. 36, 123 (2006)

20. H. Justnes, A. Van Gemert, F. Verboven, E.J. Sellevold, Adv. Cem. Res. 8, 121 (1996)

21. Z. Jiang, Z. Sun, P. Wang, Cem. Concr. Res. 35, 1539 (2005)

22. A.B. Hossain, Assessing residual stress development and stress relaxation in restrained concrete ring specimens, (PhD Dissertation, University of Purdue, 2003)

23. P. Turcry, A. Loukili, K. Haidar, G. Pijaudier-Cabot, A. Belarbi, J. Mater. Civ. Eng. 18, 46 (2006) 